\title{
A numerical study of prestressed high strength steel tubular members
}

\author{
Michaela GKANTOU $^{\mathbf{a}^{*}}$, Marios THEOFANOUS ${ }^{\mathbf{b}^{*}}$, Charalampos BANIOTOPOULOS $^{\mathbf{b}^{*}}$ \\ ${ }^{a}$ Department of Civil Engineering, Liverpool John Moores University, Liverpool L3 3AF, UK \\ ${ }^{b}$ Department of Civil Engineering, University of Birmingham, Birmingham B15 2TT, UK \\ *Corresponding authors.E-mails:m.gkantou@ljmu.ac.uk; m.theofanous@bham.ac.uk; c.baniotopoulos@bham.ac.uk
}

(C) The Author(s) 2019. This article is published with open access at link.springer.com and journal.hep.com.cn

\begin{abstract}
The structural behavior of prestressed high strength steel (HSS) tubular members is investigated through the execution of advanced finite element modeling. Numerical models are developed and validated against published experimental data on HSS tubular members subjected to different levels of initial prestress and loaded either in tension or compression. The effect of the presence or absence of grouting on the strength and ductility of the members is also considered. To numerically replicate the structural response recorded in the tests, some key modeling features including the employed numerical solver, the adopted material models and the element types warrant careful consideration. Upon developing of the finite element models, the numerically generated ultimate loads, the corresponding failure modes and the full load-deformation curves are compared to the experimental ones, indicating a successful validation. As anticipated, prestressing enhances the load-bearing capacity for the tensile members, whereas it is detrimental for the compressive ones. A series of parametric studies is performed to assess the influence of key factors on the structural response of prestressed HSS members and the obtained results are discussed. Design guidance for tensile and compressive prestressed tubular members is also provided.
\end{abstract}

KEYWORDS finite element, prestressing, tubular members, grout, high strength steel

\section{Introduction}

The application of prestressing or post-tensioning has been traditionally used in concrete structures to counteract the deflections and limit the tensile stresses generated by the applied loads during the in-service condition, thus leading to enhanced performance and more efficient design particularly for long-span applications. Work on prestressed steel structures dates back to 1950, when Magnel [1] discussed the potential material savings that could emerge from prestressing steel structures. The behavior of prestressed load-bearing steel structures was later on analyzed by Belenya [2], while a technique to erect arched trusses with sliding joints through prestressing of a cable, which also forms part of the load bearing structure, has been patented by Ellen [3]. Research on stressed-arch frames has been extensively carried out in Australia [4,5], whereas the behavior of prestressed steel structures has

Article history: Received Jul 31, 2018; Accepted Sep 22, 2018 been recently examined by a series of research studies [614]. Some of them [11-14] investigated the behavior of steel structures, in which the prestressing cables are positioned within tubular sections, hence providing a practical means of prestressing the surrounding tubular member, while also protecting the prestressing cables. A series of long span steel tubular structures that exploit the advances offered by the use of prestress has already been developed by the Australian-based company S-Squared [15].

To allow for enhanced material savings, the gains in strength and stiffness due to the application of prestress could be combined with the benefits arising from the use of higher steel grades. In particular, steels with strength over $460 \mathrm{~N} / \mathrm{mm}^{2}$ could potentially allow for lighter structures, more economic design and profound sustainability benefits. The performance of high strength steels (HSSs) has been extensively studied [16-24].

Aiming to enhance the current understanding of the structural response of prestressed HSS tubular steel 
members and structures, the present study investigates the structural performance of prestressed members employing hot-finished square hollow sections (SHS) in HSS grades via advanced finite element (FE) modeling. Steel grades S460 and S690 are considered as representative of the low and high end of the strength range considered as highstrength respectively. The investigated members are SHS and are intended to be representative of typical structural components forming the bottom chord of tubular trusses. Since a bottom chord of a truss can be subjected to either tension or compression depending on the applied load (i.e., gravity loads and snow or uplift), both tension and compression of prestressed SHS is considered. Details on the execution of the FE modeling are meticulously presented. Upon calibration of the models, a parametric study is performed to assess the influence of key factors and appropriate design recommendations are made.

\section{Numerical modeling}

The structural performance of prestressed HSS tubular members subjected to either tension or compression is investigated by means of numerical modeling with the general-purpose FE package Abaqus [25]. This section provides a detailed description of the developed $\mathrm{FE}$ models. An overview of the FE models along with the experimental program [14] upon which the validation of the FE models was based is briefly discussed in Subsection 2.1. Subsections 2.2-2.5 state the adopted numerical modeling assumptions including the employed material models, element types, constraints, boundary conditions, and interaction properties. The introduction of the initial geometric imperfections, the application of the prestress load and the type of analysis performed are discussed in Subsections 2.6, 2.7, and 2.8, respectively.

\subsection{Overview of developed FE models}

The initial stage of this research included the development of a nonlinear numerical model suitable for the simulation of tubular members subjected to different prestress levels and loaded either in tension or compression. The selection of the geometric and material properties of the simulated members was informed by a recent experimental study that reported tests on prestressed tubular members tested to failure under tensile or compressive loading [14]. The nomenclature employed herein is identical to the one employed in Ref. [14]. In the aforementioned study, the tubes employed $50 \mathrm{~mm} \times 50 \mathrm{~mm} \times 5 \mathrm{~mm}$ square hollow sections (SHS) in S460 and S690 steel grades and a 7-wire strand, with a nominal cross-sectional area of $150 \mathrm{~mm}^{2}$ and a nominal ultimate tensile stress of $1860 \mathrm{~N} / \mathrm{mm}^{2}$, which was housed inside the SHS. The members subjected to tension were two meters long, while the ones subjected to compression were one meter long. To mitigate premature buckling of the tubular members under the application of the initial prestress load, steel collars were attached to the cables along the member length. The steel collars were marginally smaller than the internal SHS dimensions, hence they would come in contact with the surrounding tube upon initiation of buckling, thus activating the stiffness of the prestressed cable to restore the members to their straight configuration. To facilitate calibration of our models, the adopted overall and cross-sectional dimensions as well as the employed steel grades were identical to the ones reported in Ref. [14].

In line with Ref. [14], for the members subjected to tension $(\mathrm{T})$, the following four prestress levels were studied for both steel grades:

1) no cable (NG);

2) a cable with a nominal level of prestress $P_{\text {nom }}$ to eliminate slack prestress (NG0);

3 ) a cable with a level of applied prestress equal to half of the optimal prestress level $0.5 P_{\text {opt }}$ (NG1);

4) a cable with an applied prestress level equal to the optimal prestress level $P_{\text {opt }}$ prestress (NG2).

Note that the optimal prestress level $P_{\text {opt }}$ is defined as the level of prestress for which both the tube and the cable yield simultaneously in tension and is given from Eq. (1) [3]:

$$
\begin{aligned}
P_{\mathrm{opt}}= & \left(\frac{A_{\mathrm{c}} A_{\mathrm{t}}}{A_{\mathrm{t}} E_{\mathrm{t}}+A_{\mathrm{c}} E_{\mathrm{c}}}\right)\left(f_{\mathrm{cy}} E_{\mathrm{t}}-f_{\mathrm{ty}} E_{\mathrm{c}}\right), \\
& \text { but } P_{\mathrm{opt}} \leqslant A_{\mathrm{t}} f_{\mathrm{ty}} \text { and } A_{\mathrm{c}} f_{\mathrm{cy}},
\end{aligned}
$$

where $A, E$, and $f_{\mathrm{y}}$ are the cross-sectional area, Young's modulus, and yield strength; the subscripts ' $c$ ' and ' $t$ ' refer to the cable, and surrounding steel tube, respectively. Fracture of the wire strands combined with necking of the surrounding tube was the observed failure mode for all members subjected to tension.

For the steel members subjected to compression (C), the following two levels of prestress were investigated:

1) no cable (NG);

2) a cable with $P_{\text {opt }}$ prestress (NG2).

The compressive members primarily failed by global buckling.

To ensure good bonding properties and corrosion resistance, grouting can be added within the tube of the members. For prestressed members subjected to tensile loading, the addition of concrete grouting is expected to have a minimal positive effect on the system's overall performance, since concrete is weak in tension. For prestressed members subjected to compression, the addition of concrete grouting is expected to lead to a significant enhancement of the compressive capacity due to the enhanced stiffness and strength of the resulting composite member. To evaluate the effect of grouting to the structural response of prestressed tubular members, two prestress levels, namely $0.5 P_{\mathrm{opt}}(\mathrm{G} 1)$ and $P_{\mathrm{opt}}(\mathrm{G} 2)$, were considered 
for the tensile grouted members $(\mathrm{T})$ and three prestress levels, namely $P_{\text {nom }}(\mathrm{G} 0), 0.5 P_{\text {opt }}(\mathrm{G} 1)$, and $P_{\text {opt }}(\mathrm{G} 2)$, for the compressive grouted members $(\mathrm{C})$. Note that $\mathrm{NG}$ and $\mathrm{G}$ stands for non-grouted and grouted members, respectively. A summary of the developed numerical models which were in line with the tested specimens in Ref. [14] is provided in Table 1.

Table 1 Summary of the developed numerical models

\begin{tabular}{lc}
\hline specimen & prestress level \\
\hline tensile members (T) & no cable (NG) \\
& a cable with $P_{\text {nom }}$ prestress (NG0) \\
& a cable with $0.5 P_{\text {opt }}$ prestress (NG1) \\
a cable with $P_{\text {opt }}$ prestress (NG2) \\
tensile grouted members (TG) & $0.5 P_{\text {opt }}(\mathrm{G} 1)$ \\
compressive members (C) & $P_{\text {opt }}(\mathrm{G} 2)$ \\
compressive grouted members (CG) & no cable (NG) \\
& a cable with $P_{\text {opt }}$ prestress (NG2) \\
$P_{\text {nom }}(\mathrm{G} 0)$ \\
$0.5 P_{\text {opt }}(\mathrm{G} 1)$ \\
$P_{\text {opt }}(\mathrm{G} 2)$
\end{tabular}

\subsection{Material modeling}

For the steel tubes, the cable and the collars, the von Mises yield criterion with isotropic hardening was employed to represent the material response. The uniaxial stress-strain response of the SHS and the cable was extracted from material coupon tests. For the steel tubes, the average material response as extracted from S460 and S690 tensile coupon tests [22] and shown in Fig. 1(a) has been adopted. For the cables, material tests found an average yield stress and Young's modulus equal to $1703 \mathrm{~N} / \mathrm{mm}^{2}$ and $130000 \mathrm{~N} / \mathrm{mm}^{2}$, respectively [14]. A 2-stage RambergOsgood model according to the equations provided in Ref. [26] has been employed to simulate the cable's response and the resulting stress-strain curve is shown in Fig. 1(b). For the steel collars, an elastic-perfectly plastic response with yield stress $355 \mathrm{~N} / \mathrm{mm}^{2}$ has been assumed, given that these components were not expected to be subjected to high stresses.

To simulate the response of concrete in both tension and compression, the concrete damaged plasticity (CDP) constitutive model [25] available in the material library of ABAQUS has been used. CDP employs a DruckerPrager type of yield surface and a non-associated flow rule to simulate the plastic response of concrete in compression and accounts for the effect of crushing in compression or cracking in tension via stiffness degradation. The values introduced for the angle of dilation $\theta$, the eccentricity, the ratio of equibiaxial to uniaxial compressive stress $f_{\mathrm{b} 0} / f_{\mathrm{c} 0}$, the ratio of the second stress invariant on the tensile meridian to that on the compressive meridian at initial yield and the viscosity parameter were $40,0.1,1.16,0.666$, and 0 , respectively, in line with Ref. [27]. The Young's

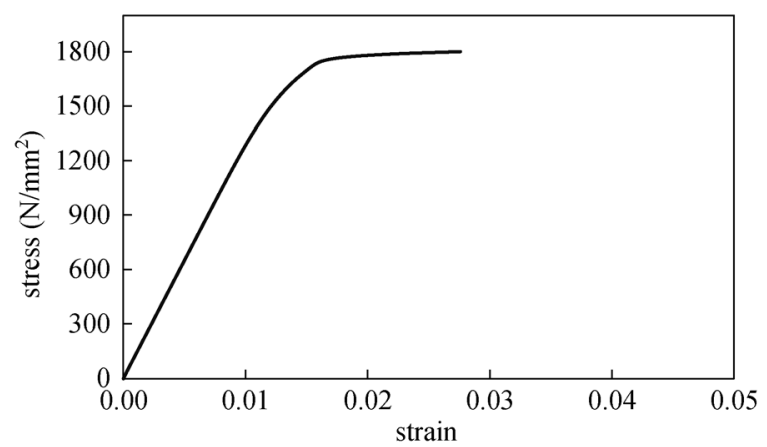

(b)

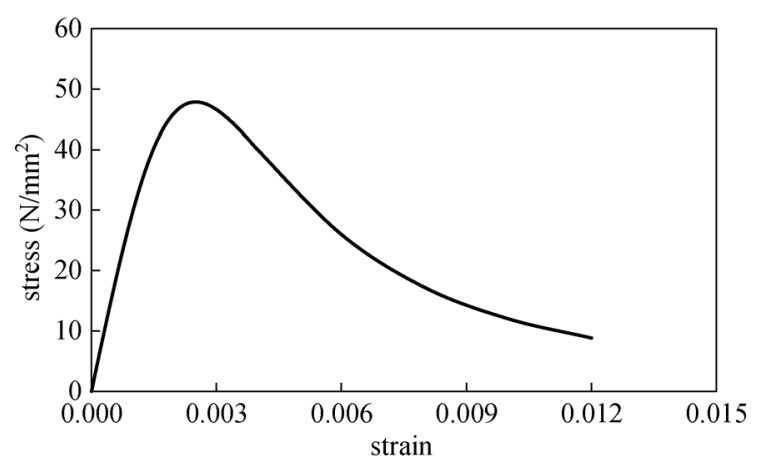

(c)

Fig. 1 Material properties. (a) Tube; (b) cable; (c) grouting. 
modulus $E$ and tensile strength $f_{\text {ct }}$ were determined according to ACI from the following equations: $E=$ $4700 \times f_{\mathrm{c}}^{0.5}$ and $f_{\mathrm{ct}}=0.33 \times f_{\mathrm{c}}^{0.5}[28]$, where $f_{\mathrm{c}}$ the grout's compressive strength equal to $50 \mathrm{~N} / \mathrm{mm}^{2}$ for the present study [14]. The Poisson's ratio was assumed equal to 0.2. The compressive stress-strain response was formulated according to the recommendations provided in Ref. [27] as shown in Fig. 1(c). The tension stiffening behavior was defined in terms of tensile stress $f_{\mathrm{ct}}$ and fracture energy, the latter evaluated equal to 0.09 , as a function of the cube's compressive strength and the aggregate's size. Note that the influence of the assumed values for the dilation angle and the fracture energy was preliminary studied, revealing minor variations in the attained response for different values of the aforementioned quantities.

Damage properties have not been included in any of the material models of the present study, since the applied loads were monotonic. The stress-strain curves were converted into the true stress-logarithmic plastic strain format before their input into the software.

\subsection{Element types}

In FE modeling, the structural parts can be simulated with different element types. The most commonly applied elements are solid, shell and beam elements. Continuum or solid elements simply model small blocks of material in a component. Shell elements approximate a three-dimensional continuum with a surface model and are used to model structures in which the one dimension (the thickness) is significantly smaller than the other dimensions and the stresses in the thickness direction are negligible. In beam elements, one dimension (the length) is significantly greater than the other two dimensions and the longitudinal stress is the most important.

An initial study examined the behavior of non-grouted prestressed members for the following three cases of employed FE element types: i) shell elements for the tube, beam elements for the cable; ii) shell elements for the tube, solid elements for the cable, solid elements for the collars; iii) solid elements for the tube, solid elements for the cable, solid elements for the collars. Similar response was achieved for all cases considered. Given that the concrete of grouted members could only be simulated with solid elements and in order to maintain consistency between grouted and non-grouted models, it was decided to further investigate model (iii). Three linear solid elements were used through the thickness of the steel tubes, to accurately capture localized bending of the tubular face should it occur. For the simulation of the cable, the 7-strand wire was simplified to a circular solid beam section with a crosssectional area equal to the effective cable area of $150 \mathrm{~mm}^{2}$. An initial mesh convergence study was performed to ensure accuracy while keeping computational time to a minimum.

\subsection{Constraints and boundary conditions}

For both compressive and tensile members a rigid body was assigned in the end sections and the motion was constrained to a reference point (RP) to facilitate the application of the boundary conditions. For tensile members, all degrees of freedom were restrained at the RPs, except for the translational degree of freedom along the longitudinal axis which was left unrestrained in one of the two ends. For compressive members, the rotational degrees of freedom around the two transverse member's axes were also left unrestrained at the RPs of the end sections. To reduce the required computational time, the symmetry in geometry, applied load and obtained response was exploited. Half of the structural system was modeled along the longitudinal axis and appropriate symmetry boundary conditions were assigned. Some typical FE models including the applied boundary conditions and constraints are shown in Fig. 2.

\subsection{Interaction properties}

A tie constraint which equates the degrees of freedom of the constrained entities using a master-slave formulation was employed to simulate the attachment of the steel collars to the cables. For the contact between (i) tube and cable and (ii) tube and collar in non-grouted members, and between (i) grouting and collar (ii) grouting and tube and (iii) grouting and cable in grouted members, the general contact algorithm of Abaqus [25] was applied. For normal contact, the "hard" contact relationship that minimises the penetration has been adopted. A friction coefficient was employed to define the tangential behavior over contacting surfaces. A preliminary parametric study demonstrated that the effect of the frictional coefficient on the overall performance is small for the given application. In line with Ref. [27], a friction coefficient equal to 0.3 was adopted for the tangential contact behavior.

\subsection{Geometric imperfections and residual stresses}

To incorporate the initial geometric imperfections in the structural system, a linear buckling analysis was initially performed and the lowest buckling mode shape corresponding to the observed failure mode was introduced in the subsequent analysis. It is noteworthy that only tie constraints have been used in the linear buckling analysis step for the extraction of the lowest elastic buckling mode shapes of the tubes, which were subsequently utilized as an initial geometric imperfection pattern. Residual stresses were of low magnitude for the hollow sections considered in the present study as documented in Ref. [22] and thus they were not explicitly modeled. 


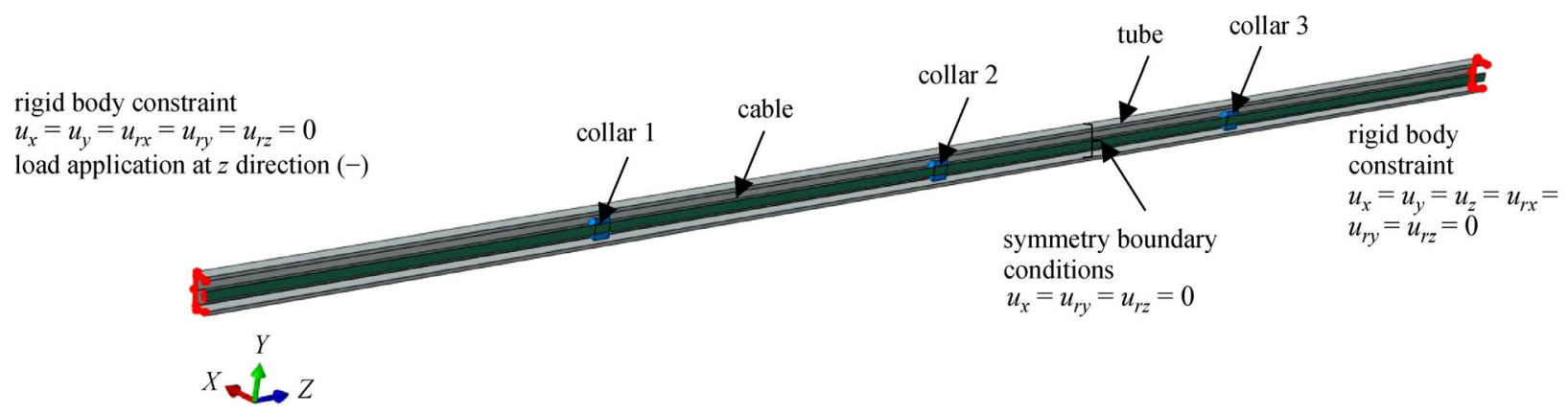

(a)

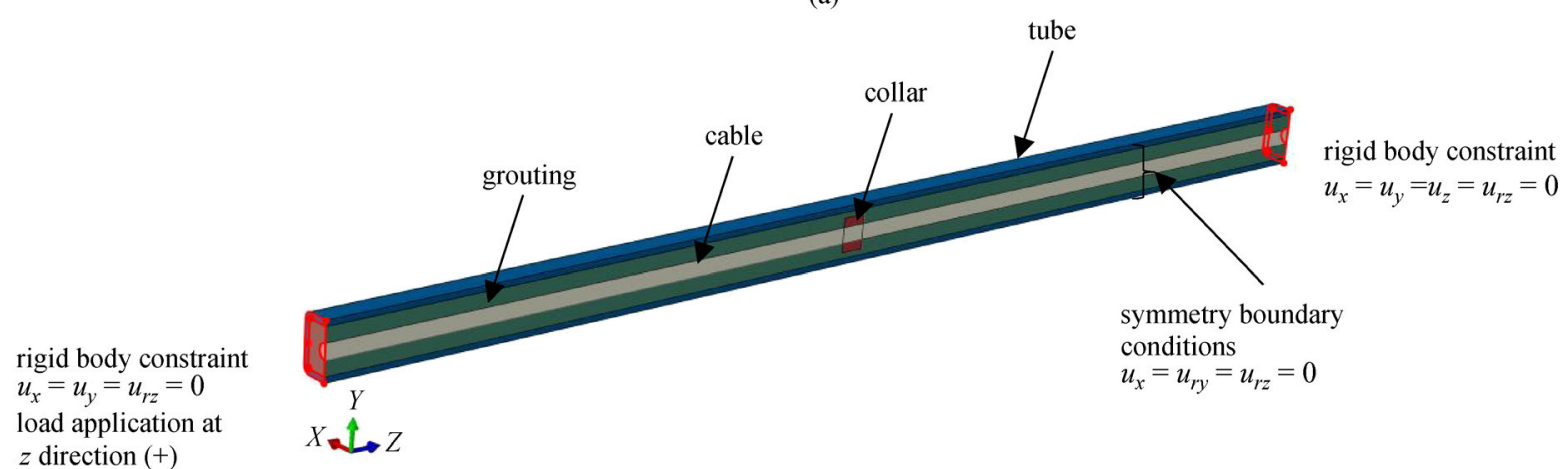

(b)

Fig. 2 Typical FE models. (a) Tensile non-grouted member; (b) compressive grouted member.

\subsection{Initial prestress}

Upon introduction of geometric imperfections, the stresses arising due to prestress were introduced through an initial static analysis. The extracted stress state was inserted as a predefined stress field in the subsequent nonlinear analysis. The introduction of the prestress resulted in a magnification of the initial geometric imperfection for the members under compression and conversely in a reduction of imperfections for the members in tension. The method of introducing the prestress as a predefined temperature field has also been found in Refs. [12,13] but the simpler, nevertheless efficient, method of executing an initial static analysis was preferred.

\subsection{Analysis techniques}

Implicit solvers and incremental-iterative procedures (e.g., Newton-Raphson) are commonly employed to determine the load-displacement equilibrium of a structure in nonlinear static problems. Even though this method appeared suitable for the compressive non-grouted specimens, the combined material, geometric and contact nonlinearities made convergence difficult for the grouted members subjected to tension. This is because the material response of concrete in tension is not monotonic and hence the stiffness matrix is not positive definite unless a technique like static stabilization or viscous regularisation is employed. For this reason and in order to maintain consistency within the whole study the explicit solver, in which the response is obtained incrementally by explicitly advancing the kinematic state from the previous increment, was applied for the analyses hereafter. The explicit solver is meant to be used for dynamic problems as it relies on a truly dynamic algorithm for time integration of the equilibrium equations, which necessitates the use of several hundreds small but computationally inexpensive increments. Given that the problem considered was static, a quasi-static analysis (i.e., a dynamic analysis over a time large enough to render inertia effects negligible) was performed. The chosen analysis period, mass scaling and smooth time-history of the applied load led ensured that the kinetic energy (ALLKE in Abaqus history output) was only a very small fraction (less than 3\%) of the internal energy (ALLIE in Abaqus history output) over the largest part of the analysis. The analyses were executed at the BlueBEAR Cluster possessed by the University of Birmingham. To mitigate dynamic oscillations after the occurrence of member buckling, large values of time periods needed to be applied for the compressive members.

\section{Validation of the FE models}

Adopting the modeling assumptions described in Section 2 , the numerical results were validated against the test data 
reported in Ref. [14]. Subsection 3.1 provides the comparison between the experimental and the numerical response of the tensile members. Subsection 3.2 focuses on the compressive members and reports an imperfection study to determine the magnitude that leads to the closest agreement with the test data. The obtained failure modes are presented in Subsection 3.3.

\subsection{Validation of model for tensile members}

The numerically obtained ultimate loads $N_{\mathrm{u}, \mathrm{FE}}$ for the simulated members in tension were compared to the experimental ones $N_{\mathrm{u}, \mathrm{Exp}}$. The results are reported in Table 2, where an excellent agreement with the experimental results can be observed. The load-deformation response of some typical cases is shown in Fig. 3, where a very good replication of the overall load-deformation response can be observed. It is noteworthy that the continuous drops in the experimental curve of Fig. 3(c) are due to the successive fracture of wires comprising the cable. This feature could be captured numerically with explicit modeling of the strands, as was done in Ref. [29], but would necessitate the explicit modeling of the actual cable geometry, the adoption of a suitable damage initiation and propagation criterion calibrated against experimental results, a very fine mesh to capture the

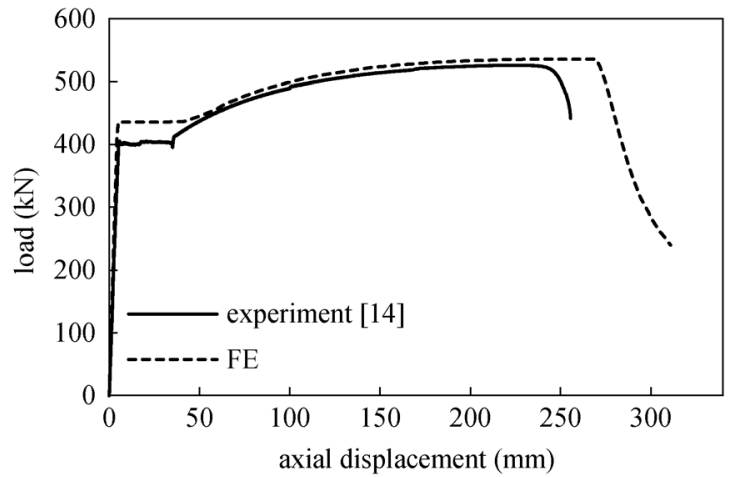

(a)

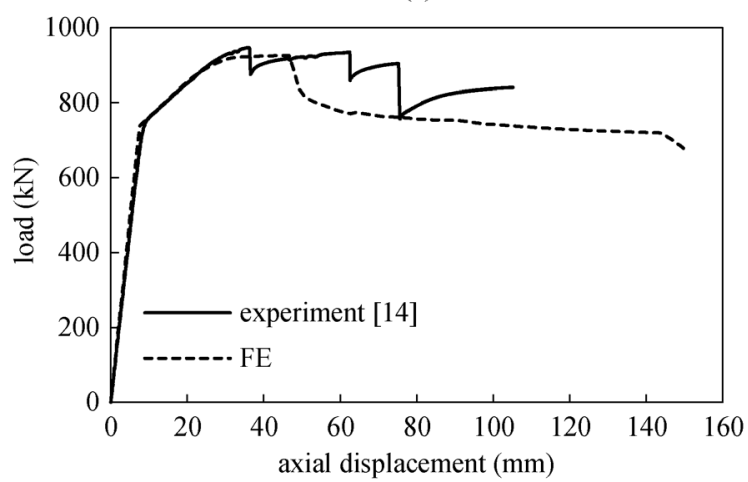

(c)
Table 2 Tensile specimens - comparison of numerical and experimental [14] ultimate loads

\begin{tabular}{lc}
\hline specimen & $N_{\mathrm{u}, \mathrm{FE}} / N_{\mathrm{u}, \mathrm{Exp}}$ \\
\hline T460NG & 1.02 \\
T460NG0 & 1.06 \\
T460NG1 & 0.98 \\
T460NG2 & 1.04 \\
T460G1 & 0.98 \\
T460G2 & 0.95 \\
T690NG & 0.94 \\
T690NG0 & 0.98 \\
T690NG1 & 0.94 \\
T690NG2 & 0.97 \\
T690G1 & 0.93 \\
T690G2 & 0.94 \\
mean & 0.98 \\
COV & 0.04 \\
\hline
\end{tabular}

localized fracture and significantly more computational time. All these were beyond the scope of the present study, as shortly upon the fracture of one wire the rest follow.

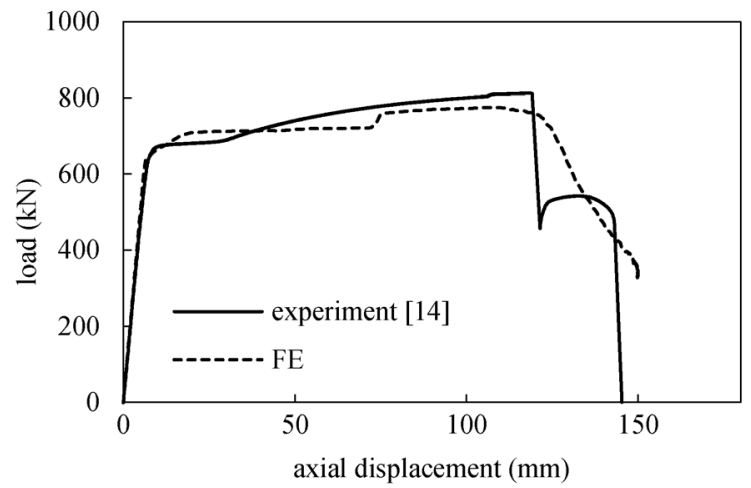

(b)

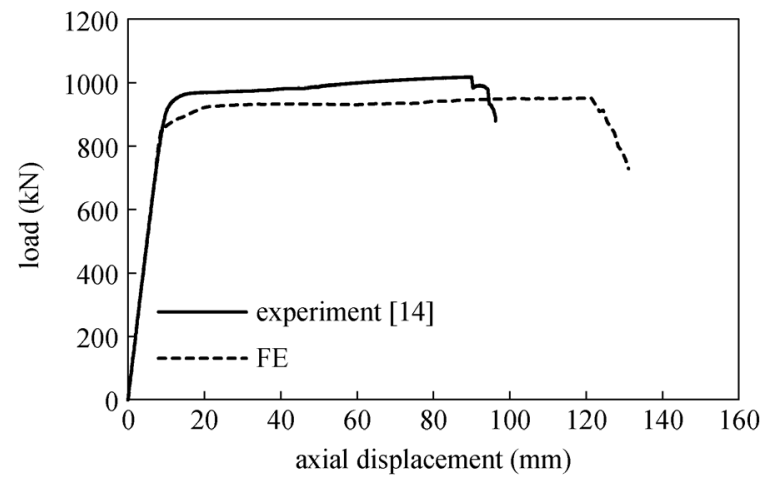

(d)

Fig. 3 Tensile specimens - comparison of numerical and experimental [14] load-deformation responses. (a) T460NG; (b) T460G2; (c) T690NG0; (d) T690G2. 


\subsection{Validation of model for compressive members}

The compressive specimens are expected to fail by global buckling and hence the amplitude of the initial geometric imperfections affects the ultimate response. To find the imperfection magnitude that results in the best agreement with the experimental results, the following six magnitudes were investigated: measured imperfection magnitudes, as given in Ref. [14], $L / 3000, L / 2000, L / 1500, L / 1000$, and $L / 750$, where $L$ the member's length. The numerically generated ultimate loads were compared to the experimental ones, as shown in Table 3. As can be seen, best agreement with a mean value of $N_{\mathrm{u}, \mathrm{FE}} / N_{\mathrm{u}, \mathrm{Exp}}=0.97$ and relatively large but still acceptable coefficient of variation, was achieved for the magnitude $L / 1000$. This magnitude has been employed in the subsequent parametric studies. The load-deformation response for the considered imperfection magnitudes was also recorded, demonstrating overall good agreement with the test response, as shown for typical cases in Fig. 4.

\subsection{Failure modes}

In addition to the comparison of the experimental to FE ultimate loads and load-deformation curves, the failure modes were also successfully replicated. Figures 5(a) and 5(b) depicts typical numerically obtained failure modes for the tensile (i.e., necking formation) and compressive (i.e., global buckling) members. The true von Mises stresses are also displayed. Note that even though no material damage has been introduced in the models, necking has been successfully captured, demonstrating that the formation of necking is a geometric and not a material instability as was demonstrated in Ref. [30]. In Fig. 5(c), the experimental failure mode [14] is compared with the numerically generated one, showing a good agreement.

\section{Parametric studies}

Based on the numerically obtained results, a series of parametric studies are performed in order to study the effect of key factors on the performance of prestressed tubular members. The parametric studies are described in Subsection 4.1, while the effect of the investigated parameters on the structural response are discussed in Subsections 4.2-4.6.

\subsection{Overview}

Upon successful validation of the FE models, a series of parametric studies were carried out in order to evaluate the effects of key parameters on the structural performance. The same modeling assumptions with those of the validated models have been adhered to, while initial geometric imperfections with a magnitude equal to $L / 1000$ where $L$ the member's length, have been adopted in all cases. The effects of the following parameters were considered: the prestress level (no cable, $P_{\text {nom }}, 0.5 P_{\text {opt }}$, $\left.P_{\text {opt }}\right)$; the effect of the presence of grouting $(\mathrm{NG}, \mathrm{G})$; the strength class of the grouting $(\mathrm{C} 25, \mathrm{C} 50, \mathrm{C} 70)$; the tube's steel grade (S460, S690); the ratio of the cross sectional area of the prestressed cable over the cross-sectional area of the tube $\left(A_{\mathrm{c}} / A_{\mathrm{t}}\right)$.

\subsection{Effect of the level of applied prestress}

To evaluate the effect of the applied level of prestress level, Fig. 6 presents the numerically obtained ultimate loads plotted against the prestress level, which is given as a percentage of the cable's yield load $\left(A_{\mathrm{c}} / f_{\mathrm{yc}}\right)$. Note that $0 \%$ prestress in the horizontal axis of Fig. 6(a) corresponds to a tensile member without any cable. As can be seen in

Table 3 Compressive specimens - comparison of numerical and experimental [14] ultimate loads

\begin{tabular}{|c|c|c|c|c|c|c|}
\hline \multirow[t]{2}{*}{ specimen } & \multicolumn{6}{|c|}{$N_{\mathrm{u}, \mathrm{FE}} / N_{\mathrm{u}, \text { Exp }}$ (imperfection magnitude) } \\
\hline & measured & $L / 3000$ & $L / 2000$ & $L / 1500$ & $L / 1000$ & $L / 750$ \\
\hline C460NG0 & 1.02 & 1.08 & 1.06 & 1.05 & 1.00 & 0.96 \\
\hline C460NG2 & 0.90 & 1.12 & 1.01 & 1.01 & 0.95 & 0.91 \\
\hline C460G0 & 1.10 & 1.16 & 1.14 & 1.11 & 1.04 & 1.00 \\
\hline C460G1 & 1.17 & 1.33 & 1.28 & 1.25 & 1.19 & 1.15 \\
\hline C460G2 & 1.17 & 1.30 & 1.17 & 1.17 & 1.14 & 1.06 \\
\hline C690NG0 & 0.95 & 0.96 & 0.95 & 0.94 & 0.92 & 0.91 \\
\hline C690NG2 & 0.88 & 0.91 & 0.89 & 0.88 & 0.86 & 0.83 \\
\hline C690G0 & 0.91 & 0.91 & 0.90 & 0.88 & 0.86 & 0.84 \\
\hline C690G1 & 0.93 & 1.02 & 1.00 & 0.99 & 0.96 & 0.94 \\
\hline C690G2 & 0.88 & 0.83 & 0.80 & 0.80 & 0.78 & 0.76 \\
\hline mean & 0.99 & 1.06 & 1.02 & 1.01 & 0.97 & 0.93 \\
\hline $\mathrm{COV}$ & 0.12 & 0.16 & 0.14 & 0.14 & 0.13 & 0.12 \\
\hline
\end{tabular}




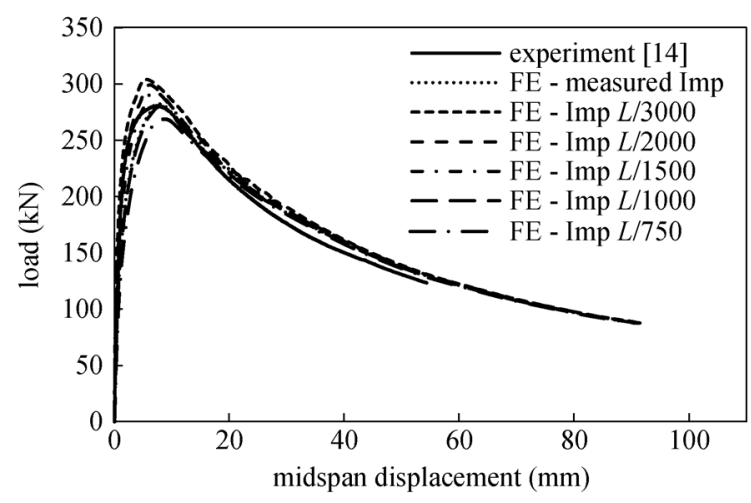

(a)

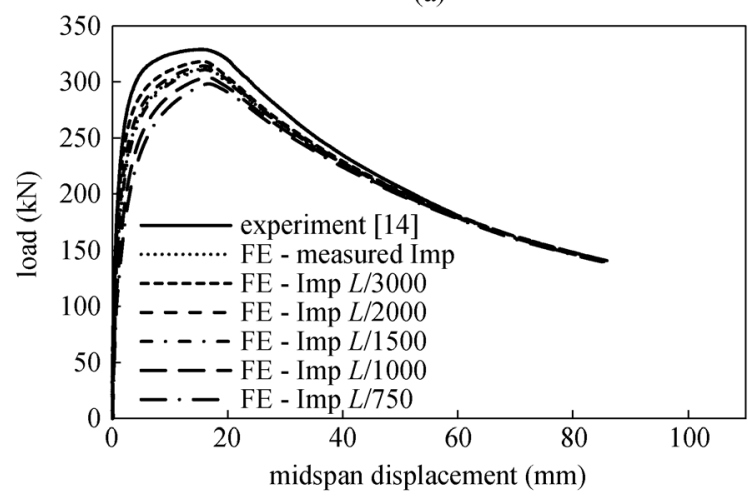

(c)

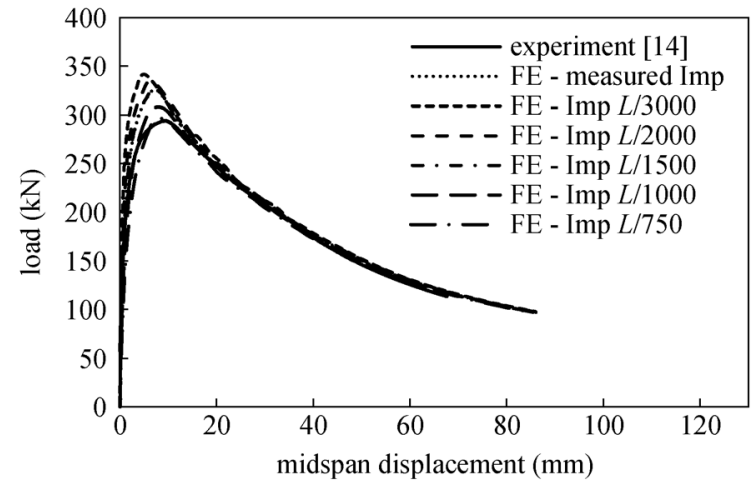

(b)

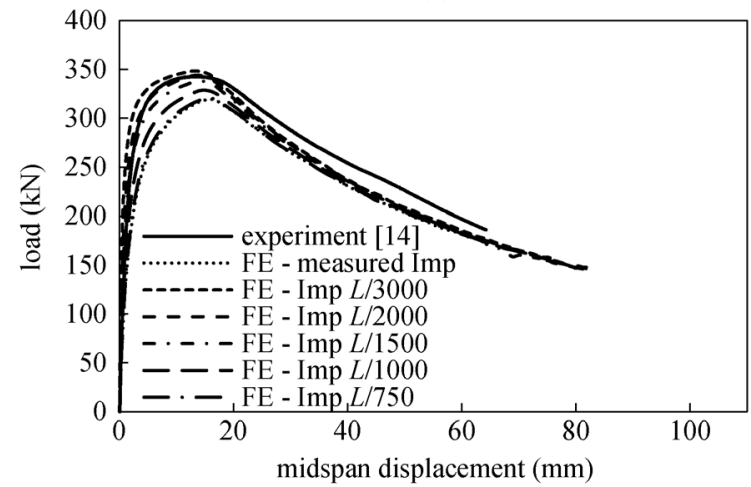

(d)

Fig. 4 Compressive specimens - comparison of numerical and experimental [14] load-deformation responses. (a) C460NG0; (b) C460G0; (c) C690NG0; (d) C690G1.

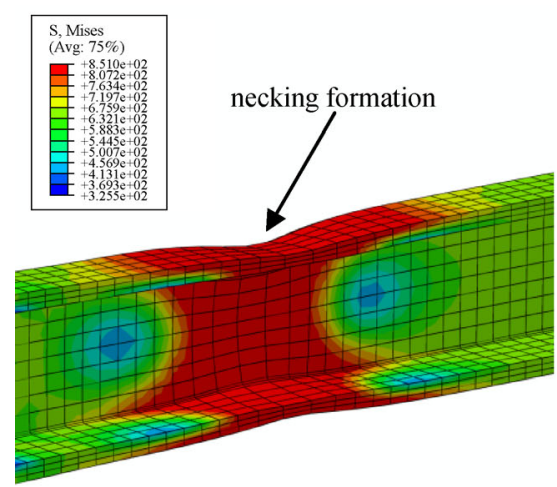

(a)

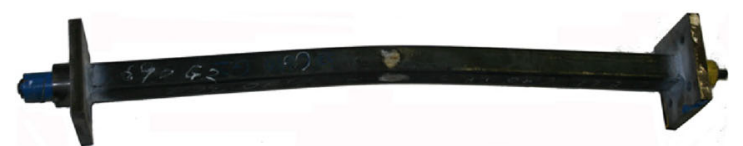

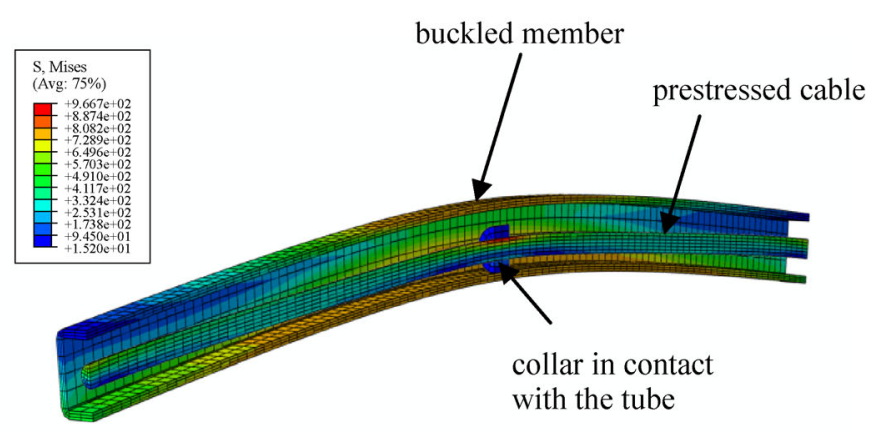

(b)

(c)

Fig. 5 Numerically obtained failure modes. (a) T690NG; (b) C690NG2; (c) comparison of experimental [14] and numerical failure mode.

Fig. 6(a), the introduction of a prestressed cable increases considerably the ultimate performance of the tensile members. A further increase is achieved with the addition of grouting. Figure 6(b) shows that the introduction of initial compressive stresses to the tube during the prestressing of the cable decreases the system's ultimate load capacity under compression. A noticeable improvement in the performance can be achieved with the addition of concrete, owing to its enhanced compressive resistance. 


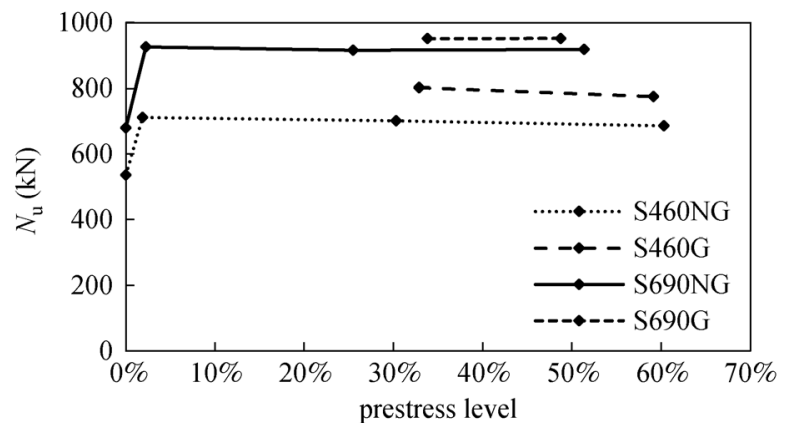

(a)

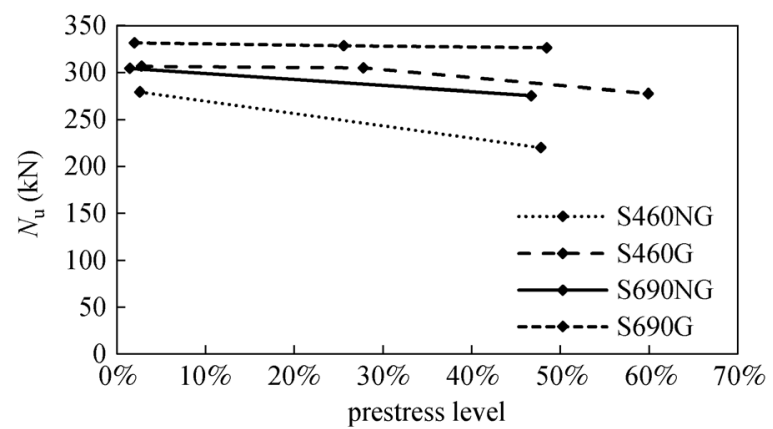

(b)

Fig. 6 Effect of the prestress level. (a) Tensile members; (b) compressive members.

\subsection{Grouting's effect}

The grouting's effect on the overall structural behavior can be seen in Fig. 7. The response of the grouted tensile members is more ductile compared to their counterparts without any grouting, as can be seen in Fig. 7(a). This is presumably due to delaying the formation of necking as the presence of grouting restricts the inwards deformation of the cross-section. For the compressive members, improvement in the performance can be achieved with the addition of concrete, owing to its enhanced compressive resistance and stiffness, as can be observed in Fig. 7(b). The presence of concrete delays the occurrence of global buckling as the member is stiffer. The results shown in Fig. 7 are for specimens in Grade S690 prestressed at optimal level, while similar conclusions are also drawn for the S460 steel grade.

\subsection{Effect of the strength class of the grouting}

Upon examining the influence of the grouting on the performance of steel members under axial loading, the effect of employing grouting of different strengths has also been studied. Three types of grouting with compressive strengths of 25,50 , and $70 \mathrm{~N} / \mathrm{mm}^{2}$, the stress-strain responses in compression of which are shown in Fig. 8(a), have been considered. It is noteworthy that the strength class of the grouting had no noticeable effect for the tensile specimens, as the increase of the system's ductility is independent from the tensile strength of the grouting which is in any case negligible and owes to the material's presence inside the tubular member that delays the necking of the specimen. The results shown in Fig. 8(b) correspond to S460 compressive grouted members prestressed at optimal level. It can be seen that as the grouting's grade increases, there is a corresponding small increase in the system's ultimate load capacity.

\subsection{Effect of the tube's steel grade}

Typical results corresponding to grouted tensile members prestressed at optimal level and non-grouted compressive members prestressed at nominal level are shown in Fig. 9. To allow the evaluation of the steel grade's effect, the applied loads are presented in a non-dimensional format. In tensile specimens, the loads are normalized by the tube's yield strength, while for the compressive ones by the tube's buckling strength, according to Ref. [31]. The more pronounced strain-hardening properties of the S460 steel grade compared to that of the $\mathrm{S} 690$ steel grade is evident in Fig. 9(a). In Fig. 9(b), it can be seen that the S460 specimen has stiffer response and larger normalized

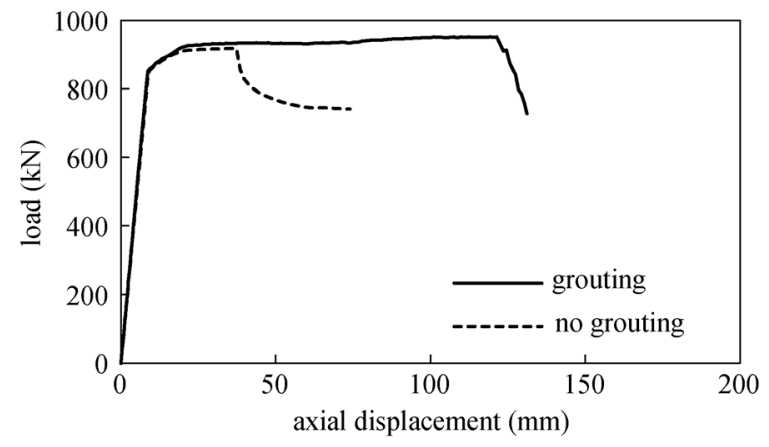

(a)

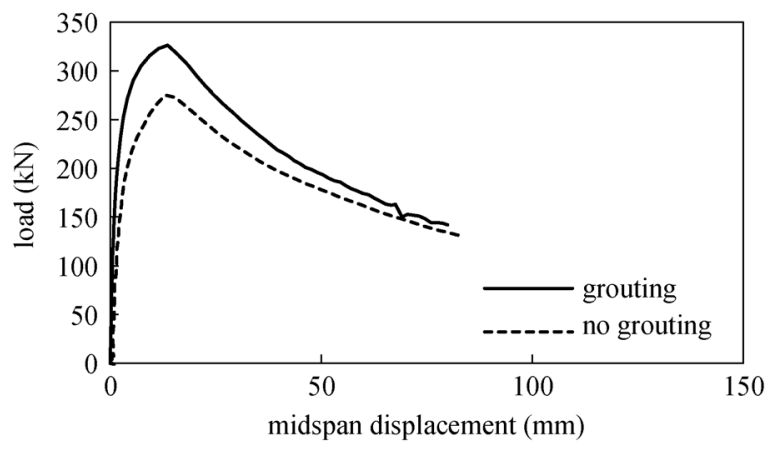

(b)

Fig. 7 Grouting's effect. (a) Tensile members; (b) compressive members. 


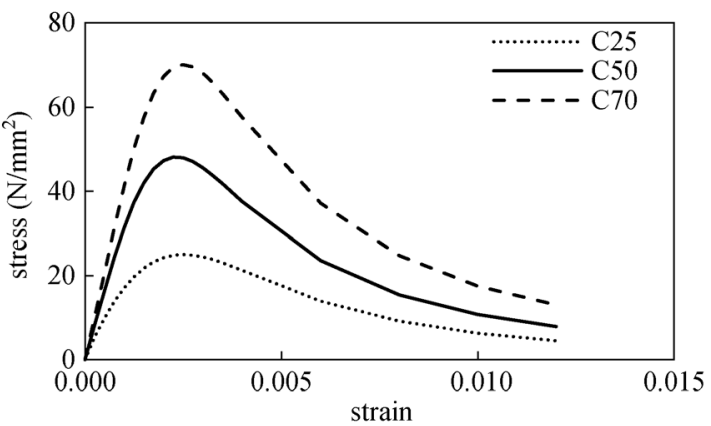

(a)

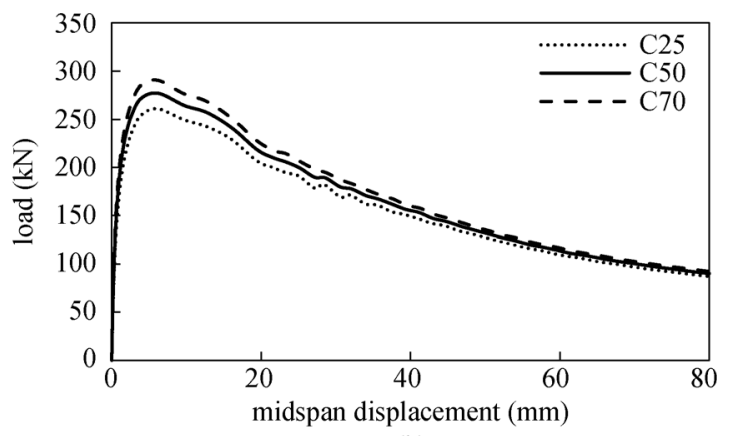

(b)

Fig. 8 Effect of the grouting's grade in compressive specimens. (a)

(a) Stress vs strain of groutings; (b) load vs midspan displacement.

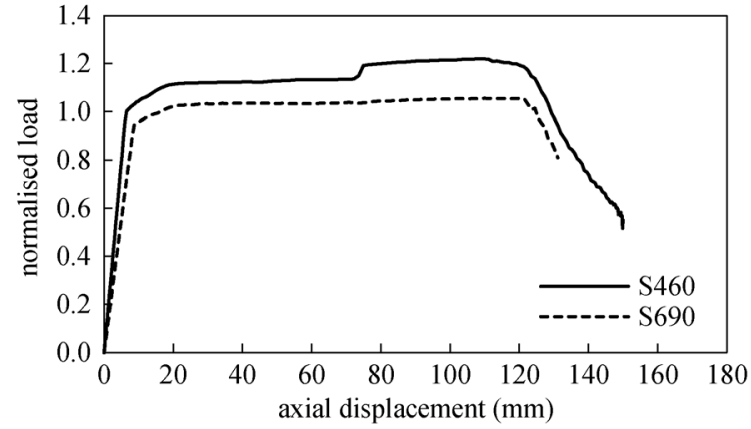

(a)

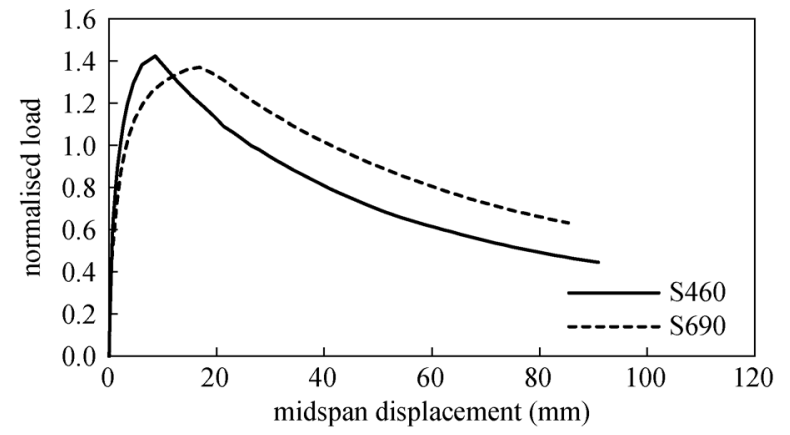

(b)

Fig. 9 Effect of the tube's steel grade. (a) Tensile members; (b) compressive members.

ultimate load compared to its counterpart in S690 steel grade. Note that similar results regarding the steel grade effect have been observed for all studied members.

\subsection{Effect of $A_{\mathrm{c}} / A_{\mathrm{t}}$}

To evaluate the influence of the cable on the system's tensile response, the effect of the ratio of the cross sectional area of the prestressed cable over the cross-sectional area of the tube $\left(A_{\mathrm{c}} / A_{\mathrm{t}}\right)$ has been examined. Keeping the tube's cross-section constant, cables in three different geometries, $A_{\mathrm{c}}=90,150$, and $260 \mathrm{~mm}^{2}$, leading to the respective $A_{\mathrm{c}} / A_{\mathrm{t}}$ ratios of $0.10,0.17$, and 0.30 , have been studied. As shown in Fig. 10(a), as the total cross-sectional area increases, the ultimate tensile performance increases as well. In Fig. 10(b), the ultimate loads of the system normalized with the tube's yield strength are plotted against the $A_{\mathrm{c}} / A_{\mathrm{t}}$ ratios, revealing a linear relationship between them.

\section{Design recommendations}

Upon comprehensive numerical study of the prestressed members, the present section provides design guidance on

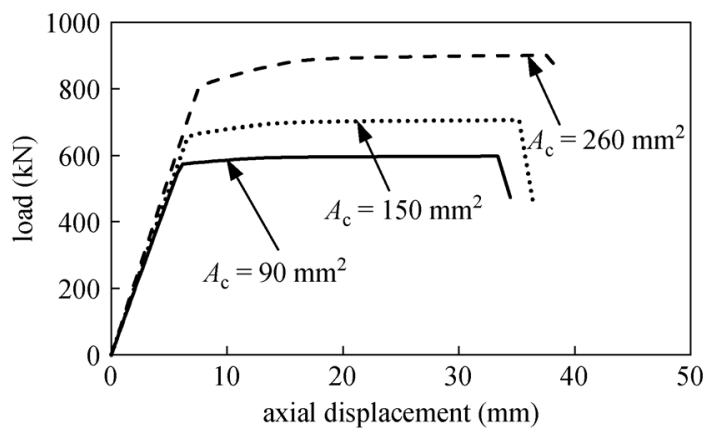

(a)

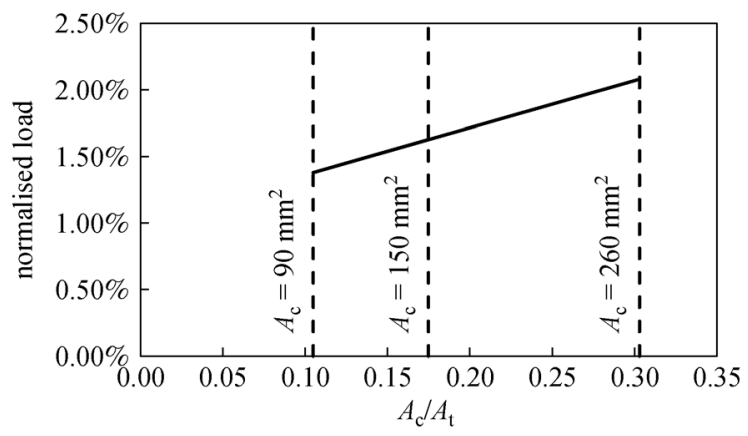

(b)

Fig. 10 Effect of $A_{\mathrm{c}} / A_{\mathrm{t}}$ in tensile specimens. (a) Load vs axial displacement; (b) increase of system's load vs $A_{\mathrm{c}} / A_{\mathrm{t}}$. 
tensile (Subsection 5.1) and compressive (Subsection 5.2) members prestressed at $P_{\mathrm{opt}}$ level.

\subsection{Design of tensile prestressed members}

When designing a prestressed member in tension, the design tensile load $N_{\mathrm{Ed}, \mathrm{t}}$ should not exceed the design plastic resistance of the chord $N_{\mathrm{pl}, \mathrm{Rd}}$ When a $P_{\mathrm{opt}}$ cable is to be inserted, the cross-sectional area of the tube and the cable can be determined according to Eq. (2).

$$
N_{\mathrm{Ed}, \mathrm{t}} \leqslant N_{\mathrm{pl}, \mathrm{Rd}}=\left(A_{\mathrm{t}} f_{\mathrm{ty}}+A_{\mathrm{c}} f_{\mathrm{cy}}\right) / \gamma_{\mathrm{M} 0},
$$

where $\gamma_{\mathrm{M} 0}$ the partial factor for resistance of cross-sections with a recommended value of 1.0 [31] and the rest as previously defined. For tensile grouted members, the contribution of grouting can be considered negligible.

\subsection{Design of compressive prestressed members}

When designing a prestressed member in compression, the design compressive load $N_{\mathrm{Ed}, \mathrm{c}}$, should not exceed the buckling resistance of the chord, as stated in Eq. (3)

$$
N_{\mathrm{Ed}, \mathrm{c}} \leqslant N_{\mathrm{b}, \mathrm{Rd}, \mathrm{p}},
$$

where $N_{\mathrm{b}, \mathrm{Rd}, \mathrm{p}}$ is the design buckling resistance of the chord, taking due account of the prestress force $P_{\mathrm{i}}$. $N_{\mathrm{b}, \mathrm{Rd}, \mathrm{p}}$ may be determined using the modified Perry-Robertson approach, proposed by Ref. [12]. Employing the same framework with Eurocode [31], the method is able to account for the effect of the prestressing cables, through Eqs. (4)-(9), where the symbols are consistent with those used in Ref. [31]. To account for member instability, the compressive resistance of the system is expressed as the plastic cross-sectional resistance multiplied by a reduction factor $\chi_{\mathrm{p}}$.

$$
N_{\mathrm{b}, \mathrm{Rd}, \mathrm{p}}=\chi_{\mathrm{p}} N_{\mathrm{pl}} / \gamma_{\mathrm{Ml}},
$$

where $\gamma_{\mathrm{M} 1}$ the partial safety factor for resistance of members to instability with a recommended value of 1.0 and $\chi_{\mathrm{p}}$ depends on the member slenderness $(\bar{\lambda})$ through Eqs. (6)-(7)

$$
\begin{aligned}
& N_{\mathrm{pl}}=A_{\mathrm{t}} f_{\mathrm{ty}}, \\
& \chi_{\mathrm{p}}=\frac{\left(1-P_{\mathrm{i}} / N_{\mathrm{pl}}\right)}{\alpha_{\mathrm{k}}\left[\phi_{\mathrm{p}}+\sqrt{\phi_{\mathrm{p}}^{2}-\frac{\left(1-P_{\mathrm{i}} / N_{\mathrm{pl}}\right)}{\alpha_{\mathrm{k}}}} \bar{\lambda}^{2}\right]}, \\
& \phi_{\mathrm{p}}=\frac{\left(1-P_{\mathrm{i}} / N_{\mathrm{pl}}\right) \bar{\lambda}^{2}+\left[\alpha_{\mathrm{k}}+\alpha(\bar{\lambda}-0.2)\right]}{2 \alpha_{\mathrm{k}}},
\end{aligned}
$$

where $\bar{\lambda}$ is the member slenderness given in Eq. (8), $\alpha_{\mathrm{k}}$ is defined in Eq. (9) and $\alpha$ is the imperfection factor, selected from Table 6.2 of Ref. [31], but on the basis of an effective yield strength of the tube, defined as $f_{\mathrm{ty}, \text { eff }}=f_{\mathrm{ty}}-P_{\mathrm{i}} / A_{\mathrm{t}}$. A buckling curve $\alpha$ with $\alpha=0.21$ is proposed for hot-finished hollow sections with $f_{\text {ty,eff }}<460 \mathrm{~N} / \mathrm{mm}^{2}$, while buckling curve $\alpha_{0}$ with $\alpha=0.13$ should be used for $f_{\text {ty,eff }} \geqslant$ $460 \mathrm{~N} / \mathrm{mm}^{2}$. Note that prestressing leads to a reduced yield strength for members under compression, thus rendering the sensitivity to geometric imperfections and effect of the residual stresses (expressed as a proportion of the yield strength) considerable for the member buckling resistance.

$$
\begin{gathered}
\bar{\lambda}=\sqrt{\frac{N_{\mathrm{pl}}}{N_{\mathrm{cr}}}}, \\
\alpha_{\mathrm{k}}=\frac{K_{\mathrm{t}}}{K_{\mathrm{c}}+K_{\mathrm{t}}},
\end{gathered}
$$

where $N_{\text {cr }}$ the elastic critical load and $K_{\mathrm{c}}$ and $K_{\mathrm{t}}$ are the axial stiffness of the cable and the tube $\left(A_{\mathrm{c}} E_{\mathrm{c}} / L\right.$ and $\left.A_{\mathrm{t}} E_{\mathrm{t}} / L\right)$, respectively.

As proposed in Ref. [12], the same design equations can be used for grouted specimens, while the grouting's contribution should be accounted for in the cross-section capacity and the slenderness $\left(\lambda_{\mathrm{g}}\right)$ evaluation, as set out in Ref. [32] from Eqs. (10)-(11)

$$
N_{\mathrm{pl}, \mathrm{g}}=\left(A_{\mathrm{t}} f_{\mathrm{ty}}+A_{\mathrm{g}} f_{\mathrm{gk}}\right),
$$

where $A_{\mathrm{g}}$ and $f_{\mathrm{gk}}$ are the cross-sectional area and the characteristic compressive cylinder strength of the grouting, respectively.

$$
\lambda_{\mathrm{g}}=\frac{L_{\mathrm{cr}}}{\pi} \sqrt{\frac{N_{\mathrm{pl}}}{E_{\mathrm{t}} I_{\mathrm{t}}+0.6 E_{\mathrm{gm}} I_{\mathrm{g}}}},
$$

where $K_{\mathrm{t}}$ and $I_{\mathrm{t}}$ are the Young's modulus and the second moment of area of the tube, $E_{\mathrm{gm}}$ and $I_{\mathrm{g}}$ are the secant modulus and the second moment of area of the grouting respectively and $L_{\mathrm{cr}}$ the effective buckling length of the tube.

\section{Conclusions}

This paper investigated numerically the ultimate response of SHS tubular members in grade S460 and S690 prestressed by a 7-wire strand embedded within the surrounding tubular members. The studied members resemble parts of the bottom chord of a prestressed truss configuration, which has been successfully employed in structural applications [3]. Both tensile and compressive loads were considered, while the grouting's effect on the structural response, commonly adopted to mitigate corrosion of the prestressing cables, was also studied. The 
generated FE models were comprehensively discussed. The numerically obtained ultimate load and load-deformation response were compared to the experimental ones, revealing a successful validation. The experimentally observed failure modes were also successfully replicated. A series of parametric studies were carried out and the influence of key factors, such as applied prestress level, ratio of cable cross-section to steel cross-section, selected steel grade and grouting strength on the structural response was extensively discussed. Overall it was shown that prestressing improves the structural performance of tensile members, while the addition of grouting leads to a more ductile behavior. For members subjected to compressive axial loading, the introduction of initial compressive stresses to the tube causes the onset of global buckling at a lower load, while the latter is moderated with the addition of grouting.

Open Access This article is licensed under a Creative Commons Attribution 4.0 International License, which permits use, sharing, adaptation, distribution and reproduction in any medium or format, as long as you give appropriate credit to the original author(s) and the source, provide a link to the Creative Commons licence, and indicate if changes were made.

The images or other third party material in this article are included in the article's Creative Commons licence, unless indicated otherwise in a credit line to the material. If material is not included in the article's Creative Commons licence and your intended use is not permitted by statutory regulation or exceeds the permitted use, you will need to obtain permission directly from the copyright holder.

To view a copy of this licence, visit http://creativecommons.org/licenses/ by/4.0/

\section{References}

1. Magnel G. Prestressed steel structures. Structural Engineer, 1950, 28(11): 285-295

2. Belenya E I. Prestressed Load-Bearing Metal Structures. Moscow: Mir Publishers, 1977

3. Ellen P E. US Patent, 4,676,045, 1987

4. Clarke M J, Hancock G J. Simple design procedure for the coldformed tubular top chord of stressed-arch frames. Engineering Structures, 1994, 16(5): 377-385

5. Clarke M J, Hancock G J. Tests and nonlinear analyses of smallscale stressed-arch frames. Journal of Structural Engineering, 1995, 121(2): 187-200

6. Madrazo-Aguirre F, Ruiz-Teran A M, Ahmer Wadee M. Dynamic behaviour of steel-concrete composite under-deck cable-stayed bridges under the action of moving loads. Engineering Structures, 2015, 103: 260-274

7. Belletti B, Gasperi A. Behavior of prestressed steel beams. Journal of Structural Engineering, 2010, 136(9): 1131-1139

8. Wadee M A, Gardner L, Osofero A I. Design of prestressed stayed columns. Journal of Constructional Steel Research, 2013, 80: 287298

9. Han K B, Park S K. Parametric study of truss bridges by the posttensioning method. Canadian Journal of Civil Engineering, 2005, 32(2): $420-429$
10. Lee K, Huque Z, Han S. Analysis of stabilizing process for stresserection of Strarch frame. Engineering Structures, 2014, 59: 49-67

11. Ellen M E, Gosaye J, Gardner L, Wadee M A. Design and construction of long-span post-tensioned tubular steel structures. Tubular structures XIV, 2012, 687-693

12. Gosaye J, Gardner L, Wadee M A, Ellen M E. Compressive behaviour and design of prestressed steel elements. Structures, 2016, 5: 76-87

13. Gosaye J, Gardner L, Ahmer Wadee M, Ellen M E. Tensile performance of prestressed steel elements. Engineering Structures, 2014, 79: 234-243

14. Wang J, Afshan S, Gardner L. Axial behaviour of prestressed high strength steel tubular members. Journal of Constructional Steel Research, 2017, 133: 547-563

15. Pt-technology. Creators of Super Powerful Structures, 2019

16. Zhou F, Tong L, Chen Y. Experimental and numerical investigations of high strength steel welded $\mathrm{H}$-section columns. International Journal of Steel Structures, 2013, 13(2): 209-218

17. Ban H, Shi G, Shi Y, Bradford M A. Experimental investigation of the overall buckling behaviour of $960 \mathrm{MPa}$ high strength steel columns. Journal of Constructional Steel Research, 2013, 88: 256266

18. Wang Y B, Li G Q, Chen S W, Sun F F. Experimental and numerical study on the behavior of axially compressed high strength steel boxcolumns. Engineering Structures, 2014, 58: 79-91

19. Kim D K, Lee C H, Han K H, Kim J H, Lee S E, Sim H B. Strength and residual stress evaluation of stub columns fabricated from $800 \mathrm{MPa}$ high-strength steel. Journal of Constructional Steel Research, 2014, 102: 111-120

20. Wang J, Afshan S, Schillo N, Theofanous M, Feldmann M, Gardner L. Material properties and compressive local buckling response of high strength steel square and rectangular hollow sections. Engineering Structures, 2017, 130: 297-315

21. Gkantou M, Theofanous M, Antoniou N, Baniotopoulos C. Compressive behaviour of high strength steel cross-sections. Proceedings of the Institution of Civil Engineers. Structures and Buildings, 2017, 170(11): 813-824

22. Wang J, Afshan S, Gkantou M, Theofanous M, Baniotopoulos C, Gardner L. Flexural behaviour of hot-finished high strength steel square and rectangular hollow sections. Journal of Constructional Steel Research, 2016, 121: 97-109

23. Gkantou M, Theofanous M, Wang J, Baniotopoulos C, Gardner L. Behaviour and design of high strength steel cross-sections under combined loading. Proceedings of the Institution of Civil Engineers. Structures and Buildings, 2017, 170(11): 841-854

24. Gkantou M, Theofanous M, Baniotopoulos C. On the structural response of high strength steel prestressed trusses. A numerical approach. In: the Proceedings of the 11th HSTAM International Congress on Mechanics. Athens, Greece, 2016, 27-30

25. Hibbitt, Karlsson and Sorensen Inc. ABAQUS, ABAQUS/Standard User's Manual, 2010

26. Gardner L, Nethercot D A. Experiments on stainless steel hollow sections- Part 1: Material and cross-sectional behaviour. Journal of Constructional Steel Research, 2004, 60(9): 1291-1318

27. Manos G C, Theofanous M, Katakalos K. Numerical simulation of the shear behaviour of reinforced concrete rectangular beam 
specimens with or without FRP-strip shear reinforcement. Advances in Engineering Software, 2014, 67: 47-56

28. ACI Committee 318. Building Code Requirements for Structural Concrete and Commentary (ACI 318-99). Detroit (MI): American Concrete Institute, 1999

29. Abdullah A B M, Rice J A, Hamilton H R, Consolazio G R. An investigation on stressing and breakage response of a prestressing strand using an efficient finite element model. Engineering Structures, 2016, 123: 213-224
30. Okazawa S, Usami T, Noguchi H, Fujii F. Three-dimensional necking bifurcation in tensile steel specimens. Journal of Engineering Mechanics, 2002, 128(4): 479-486

31. British Standard. EN 1993-1-1. BS EN 1993-1-1: 2005 + A1:2014, Eurocode 3: Design of steel structures, Part 1-1: General rules and rules for buildings. London: BSI, 2014

32. European Standard. EN 1994-1-1. Eurocode 4: Design of composite steel and concrete structures, Part 1-1: General rules and rules for buildings. Brussels: CEN, 2004 